\title{
Impact of Crack on Stability of Slope with Linearly Increasing Undrained Strength
}

\author{
Bing Li, ${ }^{1}$ Fei Zhang $\left(\mathbb{D},{ }^{2}\right.$ and Di Wang ${ }^{2}$ \\ ${ }^{1}$ Key Laboratory of Concrete and Prestressed Concrete Structures of the Ministry of Education, Southeast University, \\ No. 2, Sipailou, Nanjing 210096, China \\ ${ }^{2}$ Key Laboratory of Ministry of Education for Geomechanics and Embankment Engineering, Hohai University, \\ No. 1, Xikang Road, Nanjing 210098, China \\ Correspondence should be addressed to Fei Zhang; feizhang@hhu.edu.cn
}

Received 13 September 2017; Revised 22 February 2018; Accepted 18 March 2018; Published 30 April 2018

Academic Editor: J.-C. Cortés

Copyright (C) 2018 Bing Li et al. This is an open access article distributed under the Creative Commons Attribution License, which permits unrestricted use, distribution, and reproduction in any medium, provided the original work is properly cited.

\begin{abstract}
This paper presents a procedure for assessment of the impact of tension crack on stability of slope in clays with linearly increasing undrained strength. The procedure is based on the limit equilibrium method with variational extremization. The distribution of the normal stress over slip surface is mathematically obtained for slopes in clays with the linearly increasing undrained strength and then used to determine the tension crack for clays with zero tensile strength. The seismic effect is also included using the pseudostatic approach. Closed-form solutions to the minimum safety factor and the maximum crack depth can be derived and given in the form of chart for convenient use. The results demonstrate a significant effect of the tension crack on the stability of steep slopes, especially for strong seismic conditions. In this situation, neglecting the impact of tension crack in traditional $\phi=0$ analyses may overestimate the slope safety. The most adverse location of the tension crack can be also determined and presented in the charts, which may be useful in designing reinforcements and remedial measures for slope stabilization.
\end{abstract}

\section{Introduction}

Slopes in clays are usually under short-term undrained conditions, such as slopes at the end of construction, slopes subjected to earthquakes, and rapid excavations. In these situations, the traditional $\phi=0$ limit equilibrium (LE) analysis is carried out to assess the stability of slopes. The pore water pressure is not considered in the total stress analysis and using the undrained strength of clays can determine the factor of safety of slopes. Taylor [1] first adopted an average constant shear strength for clays $\left(c_{\mathrm{u}}\right)$ into the undrained LE analysis and presented a classical stability chart for slope stability assessment. Through experimental observations, the normal consolidated clays exhibit a linear increase of the undrained shear strength with depth as

$$
c_{\mathrm{u}}=c_{\mathrm{u} 0}+k z,
$$

where $c_{\mathrm{u} 0}$ is undrained strength at the ground surface and $k$ is gradient at which undrained strength increases with depth $z$. Gibson and Morgenstern [2] adopted the linear increasing undrained strength with $c_{\mathrm{u} 0}=0$ into the $\phi=0$ analysis and then established an expression to calculate the factor of safety. Hunter and Schuster [3] then extended this expression to account for $c_{\mathrm{u} 0}>0$. Similar problems for stability assessment were further addressed by many investigators [4-8]. Based on the theory of soil plasticity, Booker and Davis [9] and Chen et al. [10] proposed kinematical approach of limit analysis (LA) to obtain the upper-bound solution for this slope problem. Yu et al. [11] used finite-element LA method to calculate the lower- and upper-bound solutions and compared with LE results from the $\phi=0$ analysis. Their solutions were given in the form of charts for convenient use in practice. The $\phi=0$ method is also used to assess stability of embankments over soft ground. Leshchinsky and Smith [12] and Low [13] adopted the LE method to calculate the factor of safety of embankments constructed on the soft clay. The undrained strength of the clay is linearly increasing with the depth. Chai et al. $[14,15]$ employed the finite-element (FE) method to back analyze the failure of an embankment on clay deposit. 


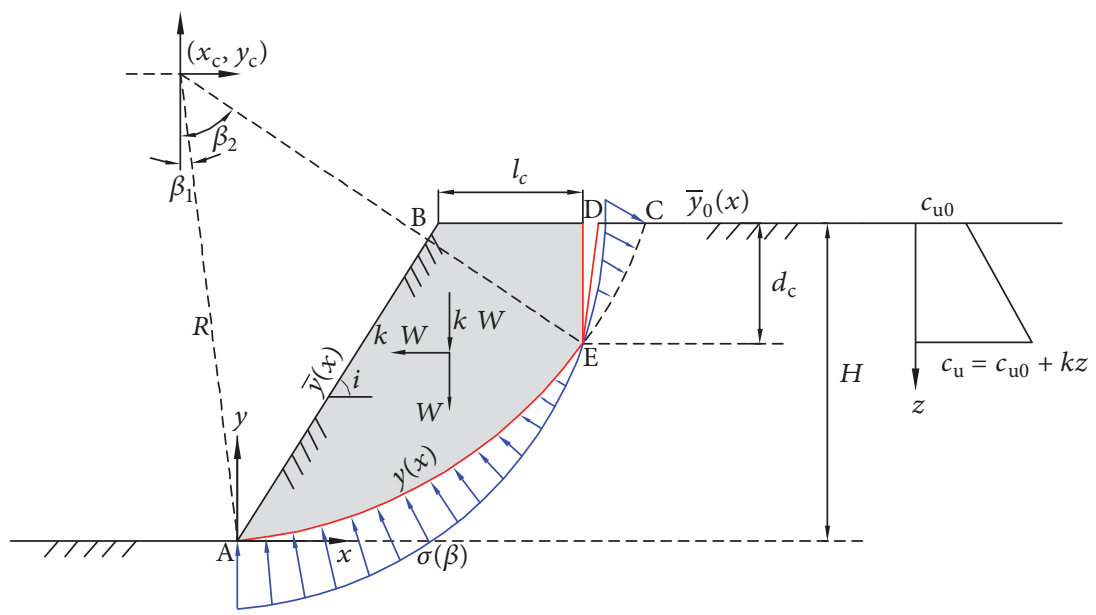

FIGURE 1: Notation and convention for the stability analysis of slope with tension crack.

Based on the $\phi=0$ analysis of slope stability, Nakase [17] extended it into stability analysis of low embankment on cohesive soil stratum. A vertical tension crack is involved to obtain more critical circular slip surface, but the depth of the crack is assumed. Actually, many investigations after slope failures indicate that tension cracks often occur at the crest of slopes in clays. Baker and Leshchinsky [18] utilized the safety map proposed by Baker and Leshchinsky [19], to explore the spatial distribution of safety factors in in a vertical purely cohesive cut. Their derived results demonstrate that the tension crack would be formed in vertical cut with zero tensile strength of soil and result in a significant decrease on the factor of safety by $70 \%$. Some efforts have been made by Baker [20], Utili [21], and Michalowski [22], to investigate the impacts of the tension crack on slope stability. However, their studies are focused on stability of slopes under drained conditions. The purpose of this paper is to include the effects of tension crack into stability analyses of undrained slopes. The undrained strength of clays is assumed to linearly increase from the slope crest. Based on the variational analysis of slope stability by Baker [20], a procedure is developed to obtain a closed-form solution for evaluating the effects of tension crack on the slope stability.

\section{Variational Analysis of Clay Slope Stability with Tension Crack}

2.1. Definition and Formulation of Problem. Figure 1 illustrates a slope in clay with linearly increasing undrained strength and its corresponding potential the slip surface. The LE formulation follows the notations presented by Baker [20] and Leshchinsky and San [23]. A brief description of the relevant formulae is given here for clarity. For convenience of presentation of results, the following nondimensional parameters are introduced first (see Figure 1):

$$
\begin{aligned}
& X=\frac{x}{H}, \\
& Y=\frac{y}{H},
\end{aligned}
$$

$$
\begin{aligned}
\bar{Y} & =\frac{\bar{y}}{H}, \\
\overline{Y_{0}} & =\frac{\bar{y}_{0}}{H}, \\
D_{\mathrm{c}} & =\frac{d_{\mathrm{c}}}{H}, \\
L_{\mathrm{c}} & =\frac{l_{\mathrm{c}}}{H}, \\
N_{0} & =\frac{c_{\mathrm{u} 0}}{\gamma H F}, \\
\lambda & =\frac{k H}{c_{\mathrm{u} 0}}, \\
S & =\frac{\sigma}{\gamma H}, \\
T & =\frac{t}{\gamma H F},
\end{aligned}
$$

where $y(x), \bar{y}(x)$, and $\bar{y}_{0}(x)$ represent the equation of the slip surface, the slope surface, and the top surface; $d_{c}$ and $l_{c}$ are the depth of the tension crack and its horizontal distance on the crest from the slope; $\sigma$ is normal stress along the slip surface; $t$ is tensile strength; $\gamma$ is unit weight; $H$ is slope height; $\lambda$ is cohesion coefficient; $F$ is reduction factor of soil strength. Using these nondimensional parameters, the force or moment equilibrium equations can be obtained for the soil mass bounded by the slip surface and the soil surface. To account for the seismic effects, the pseudostatic approach is adopted here. Similar to the procedure of Baker [20], the horizontal force, vertical force, and moment equilibrium equations are given for a slope in clay with linearly increasing undrained strength as

$$
\begin{aligned}
\bar{H} & =\int_{X_{1}}^{X_{2}}\left\{N_{0}\left[1+\lambda\left(\bar{Y}_{0}-Y\right)\right]-S Y^{\prime}\right. \\
& \left.-k_{\mathrm{h}}(\bar{Y}-Y)\right\} d X=0
\end{aligned}
$$




$$
\begin{aligned}
\bar{V} & =\int_{X_{1}}^{X_{2}}\left\{N_{0}\left[1+\lambda\left(\bar{Y}_{0}-Y\right)\right] Y^{\prime}-\left(1+k_{\mathrm{v}}\right)(\bar{Y}-Y)\right. \\
& +S\} d X=0 \\
\bar{M} & =\int_{X_{1}}^{X_{2}}\left[N_{0}\left[1+\lambda\left(\bar{Y}_{0}-Y\right)\right]\left(Y-X Y^{\prime}\right)\right. \\
& +\left(1+k_{\mathrm{v}}\right)(\bar{Y}-Y) X \\
& \left.+k_{\mathrm{h}}(\bar{Y}-Y) \frac{\bar{Y}+Y}{2}\right] d X=0
\end{aligned}
$$

where $k_{\mathrm{h}}$ and $k_{\mathrm{v}}$ are the horizontal and vertical seismic acceleration coefficient, respectively. There are an unknown parameter $F$ and two unknown functions $Y(X)$ and $S(X)$ in these equations. The unknown parameter $F$ can be explicitly expressed through any one of the three equilibrium equations ((3a), (3b), (3c)), but the two equations left must be satisfied simultaneously. Such a problem can be solved as a standard isoperimetric problem, to render the minimum value of $F$ (i.e., the factor of safety $F_{s}$ ). As presented by Baker and Garber [24], using the variational calculus principles can find a pair of functions $Y(X)$ and $S(X)$ to determine the factor of safety. The details of the variational derivation can be found elsewhere $[20,24,25]$. To find the functions, an auxiliary functional $G$ is defined here:

$$
\begin{aligned}
G & =\int_{X_{1}}^{X_{2}} g d X \\
& =\int_{X_{1}}^{X_{2}}\left\{N_{0}\left[1+\lambda\left(\bar{Y}_{0}-Y\right)\right]-S Y^{\prime}-k_{\mathrm{h}}(\bar{Y}-Y)\right\} \\
& +\lambda_{1}\left\{N_{0}\left[1+\lambda\left(\bar{Y}_{0}-Y\right)\right] Y^{\prime}-\left(1+k_{\mathrm{v}}\right)(\bar{Y}-Y)\right. \\
& +S\}+\lambda_{2}\left[N_{0}\left[1+\lambda\left(\bar{Y}_{0}-Y\right)\right]\left(Y-X Y^{\prime}\right)\right. \\
& \left.+\left(1+k_{\mathrm{v}}\right)(\bar{Y}-Y) X+k_{\mathrm{h}}(\bar{Y}-Y) \frac{\bar{Y}+Y}{2}\right] d X,
\end{aligned}
$$

where parameters $\lambda_{1}$ and $\lambda_{2}$ are Lagrange's undetermined multipliers. Based on the variational theorem of the isoperimetric problem, the functions $Y(X)$ and $S(X)$ which minimize the functional $G$ must satisfy the following two Euler differential equations:

$$
\begin{gathered}
\frac{d}{d X}\left[\frac{\partial g}{\partial S^{\prime}}\right]-\frac{\partial g}{\partial S}=0 \\
\frac{d}{d X}\left[\frac{\partial g}{\partial Y^{\prime}}\right]-\frac{\partial g}{\partial Y}=0 .
\end{gathered}
$$

Applying the first Euler differential equation (see (5a)), the function $Y(X)$ can be obtained. The geometry of the critical slip surface for slopes in frictional soil $(\phi \geq 0)$ is a logspiral. In the special case of $\phi=0$, the slip surface degenerates to a circle. Therefore, the expression of slip surface can be given in Cartesian coordinate system as

$$
\begin{aligned}
& X=X_{\mathrm{c}}+A \sin \beta \\
& Y=Y_{\mathrm{c}}-A \cos \beta,
\end{aligned}
$$

where $A$ is radius of the circular slip surface; point $\left(X_{c}, Y_{c}\right)$ is the rotational origin. Accounting the seismic effects as Leshchinsky and San [23] and Ling et al. [26], the function of the normal stress over the circular slip surface can be derived using the second Euler's equation (see (5b)) as

$$
\begin{aligned}
S(\beta)= & A\left[\left(1+k_{\mathrm{v}}\right) \cos \beta-k_{\mathrm{h}} \sin \beta\right] \\
& +2 N_{\mathrm{m} 0} \beta\left[1+\lambda\left(\overline{Y_{0}}-\overline{Y_{\mathrm{c}}}\right)\right]+3 A \lambda N_{\mathrm{m} 0} \sin \beta \\
& +B,
\end{aligned}
$$

where stability number $N_{\mathrm{m} 0}=c_{\mathrm{u} 0} / \gamma H F_{\mathrm{s}} ; B$ is unknown constant of integration.

2.2. Closed-Form Solution. To obtain some insight into the mathematical behavior of the variationally extremized results (i.e., the geometry of the critical slip surface and the distribution of the normal stress over the slip surface), a closed-form solution can be developed for evaluation of the stability of a given slope with tension crack. Based on the following relations, a detailed procedure is given to determine the stability number $N_{\mathrm{m} 0}$ for given slope angle $i$, cohesion coefficient $\lambda$, and seismic acceleration $k_{\mathrm{h}}$ and $k_{\mathrm{v}}$.

\section{(a) Geometrical Boundary Condition}

$$
\begin{aligned}
& Y\left(X=X_{1}\right)=0 \\
& Y\left(X=X_{2}\right)=1-D_{c} .
\end{aligned}
$$

Combining the equations of the slip surface (see (6)) and these geometrical boundary conditions, one can obtain the following:

$$
\begin{aligned}
A & =\frac{1-D_{\mathrm{c}}}{\cos \beta_{1}-\cos \beta_{2}} \\
Y_{\mathrm{c}} & =A \cos \beta_{1} .
\end{aligned}
$$

(b) Stress Boundary Condition

$$
S_{2}=S\left(\beta=\beta_{2}\right) .
$$

Using this relation into (6) or (7) and solving for $B$,

$$
\begin{aligned}
B= & S_{2}-A\left[\left(1+k_{\mathrm{v}}\right) \cos \beta_{2}-k_{\mathrm{h}} \sin \beta_{2}\right] \\
& -2 N_{\mathrm{m} 0} \beta_{2}\left[1+\lambda\left(\overline{Y_{0}}-\overline{Y_{\mathrm{c}}}\right)\right]-3 A \lambda N_{\mathrm{m} 0} \sin \beta_{2} .
\end{aligned}
$$

(c) Limiting Equilibrium Equations for the Sliding Body. Introducing the polar coordinate system, the mobilized strength, the extremized results on the geometry of slip surface (see (6)) 
and the distribution of normal stress (see (7)) into the three equilibrium equations, the laborious integration can be given as follows:

$$
\begin{aligned}
h^{*} & =0 \\
v^{*} & =0 \\
m^{*} & =m_{1}+N_{\mathrm{m}} m_{2},
\end{aligned}
$$

where

$$
\begin{aligned}
h^{*} & =N_{\mathrm{m} 0} \int_{\beta_{1}}^{\beta_{2}}\left[1+\lambda\left(1-Y_{\mathrm{c}}+A \cos \beta\right)\right] A \cos \beta d \beta \\
& -\int_{\beta_{1}}^{\beta_{2}} S(\beta) A \sin \beta d \beta-k_{\mathrm{h}} W_{1} \\
v^{*} & =N_{\mathrm{m} 0} \int_{\beta_{1}}^{\beta_{2}}\left[1+\lambda\left(1-Y_{\mathrm{c}}+A \cos \beta\right)\right] A \sin \beta d \beta \\
& -\int_{\beta_{1}}^{\beta_{2}} S(\beta) A \cos \beta d \beta-\left(1+k_{\mathrm{v}}\right) W_{1} \\
m_{1} & =\left(1+k_{\mathrm{v}}\right) W_{2}+k_{\mathrm{h}} W_{3} \\
m_{2} & =\int_{\beta_{1}}^{\beta_{2}}\left[1+\lambda\left(1-Y_{\mathrm{c}}+A \cos \beta\right)\right]\left(-\frac{A}{\cos \beta}\right) A \\
& \cdot \cos \beta d \beta \\
& =-A^{2} \int_{\beta_{1}}^{\beta_{2}}\left[1+\lambda\left(1-Y_{\mathrm{c}}+A \cos \beta\right)\right] d \beta \\
& -\frac{\cot i}{2}\left(Y_{\mathrm{c}}-\frac{2}{3}\right) \cdot \\
& =\int_{\beta_{1}}^{\beta_{2}}\left(A \cos \beta+1-Y_{\mathrm{c}}\right) \frac{A \cos \beta+Y_{\mathrm{c}}-1}{2} A \\
W_{1} & =\int_{X_{1}}^{X_{2}}(\bar{Y}-Y) d X=\int_{\beta_{1}}^{\beta_{2}}\left(A \cos \beta+1-Y_{\mathrm{c}}\right) A \\
& \cdot \cos \beta d \beta-\left(-X_{\mathrm{c}}-A \sin \beta_{1}\right)-\frac{\cot i}{2} \\
W_{3} & \cdot \int_{X_{1}}^{X_{2}}(\bar{Y}-Y) \frac{(\bar{Y}+Y)}{2} d X \\
W_{2} & =\int_{X_{1}}^{X_{2}}(\bar{Y}-Y) X d X=\int_{\beta_{1}}^{\beta_{2}}\left(A \cos \beta+1-Y_{\mathrm{c}}\right) \\
& -X_{\mathrm{c}}+A \sin \beta_{1} \mid \cot i \\
2 & \frac{\cot i}{3}-X_{\mathrm{c}} \mid
\end{aligned}
$$

\section{(e) Criterion for Tension Crack}

$$
\begin{aligned}
\lim S(X, Y) & =-T \\
X & \longrightarrow X_{2} \\
Y & \longrightarrow 1-D_{c} .
\end{aligned}
$$

Applying this relation at point E (see Figure 1) and finding that at this point $(\bar{Y}-Y)=D_{c}$, one gets

$$
\begin{aligned}
S\left(\beta_{2}\right)= & -N_{\mathrm{m} 0}\left[1+\lambda\left(1-Y_{\mathrm{c}}+A \cos \beta_{2}\right)\right] \cot \beta_{2} \\
& +\left(1+k_{\mathrm{v}}\right) D_{\mathrm{c}}+\frac{(1 / 2) k_{\mathrm{h}} D_{\mathrm{c}}\left(2+2 Y_{\mathrm{c}}-D_{\mathrm{c}}\right)}{A \sin \beta_{2}} .
\end{aligned}
$$

As Baker [20] discussed, when the transversality condition is applied at point of the exit of slip surface, an alternative relation based on a physical interpretation can be found as follows:

$$
X_{c}= \begin{cases}\frac{\cot i}{2} & \text { if } L \leq 0 \\ -A \sin \beta_{1} & \text { if } L>0\end{cases}
$$

When the tension crack occurred, the following condition should exist:

$$
S\left(\beta=\beta_{2}\right)=-T \text {. }
$$

Substituting (21) into (20), one obtains

$$
s^{*}=S_{2}+T=0
$$

The clay usually has zero tensile strength and then using $T=0$ yields $S_{2}=0$. 
TABLE 1: Comparisons of stability number $N_{\mathrm{m} 0}$ for $i=45^{\circ}$ between LE results of Koppula [6] and the results of this study.

\begin{tabular}{lccc}
\hline$\lambda$ & LE result [6] & \multicolumn{2}{c}{ Closed-form solution (this study) } \\
& & No crack & Tension crack \\
\hline 0.5 & 0.1244 & 0.1244 & 0.1267 \\
1.0 & 0.0984 & 0.0985 & 0.0997 \\
2.0 & 0.0697 & 0.0698 & 0.0703 \\
3.0 & 0.0541 & 0.0541 & 0.0544 \\
4.0 & 0.0442 & 0.0442 & 0.0444 \\
5.0 & 0.0374 & 0.0374 & 0.0375 \\
10.0 & 0.0211 & 0.0211 & 0.0212 \\
\hline
\end{tabular}

Based on these equations, using a computation scheme can obtain the closed-form solutions. As Baker [20] and Leshchinsky and San [23] demonstrated, the problem is reduced to solving a set of three nonlinear simultaneous equations (i.e., (12a), (12b), and (22)). To find the corresponding three roots $\left(\beta_{1}, \beta_{2}\right.$, and $\left.D_{c}\right)$, the steepest descent algorithm numerical technique is utilized here. The conventional steepest descent method can be easily followed in elsewhere (e.g., Burden and Faires [27]).

\section{Results and Discussions}

3.1. Comparisons. In the static conditions $\left(k_{\mathrm{h}}=k_{\mathrm{v}}=0\right)$, the calculated closed-form solutions can be compared with LE results given by Koppula [6], as shown in Table 1. The closedform solutions for slopes without cracks are also calculated and then given in Table 1. It should be noted that the analyses of Koppula [6] excluded the tension crack on the slope stability. Neglecting the impacts of tension crack, the closedform solutions are in good agreement with the LE results of Koppula [6]. However, accounting its impacts can yield more critical results on the stability number or the factor of safety. The impacts become insignificant as the cohesion coefficient $\lambda$ increases, because no cracks occurred.

As presented by Leshchinsky et al. [28], the variationally derived solutions can be also regarded as an upper bound in LA. Based on finite-element limit analysis method, Li et al. [16] obtained lower- and upper- bound solutions for vertical slopes under undrained conditions. Those numerical lowerand upper-bound LA solutions are also compared with the closed-form solutions of this study, as shown in Table 2. The results are given in the form of the stability number $N_{\mathrm{m} 0}=$ $c_{\mathrm{u} 0} / \gamma H F_{s}$. Due to its reciprocity of the factor of safety, the upper bound is under the lower bound for the numerical results. It can be seen that when the effect of tension crack is ignored, the derived closed-form solutions are bracketed between the lower bounds and the upper bounds, especially closer to the numerical lower-bound solutions. It implies that the variationally derived solutions are more critical than the numerical upper bounds. The numerical LA method of Li et al. [16] is based on continuum mechanics and cannot consider the open crack in clay. The closed-form solutions for

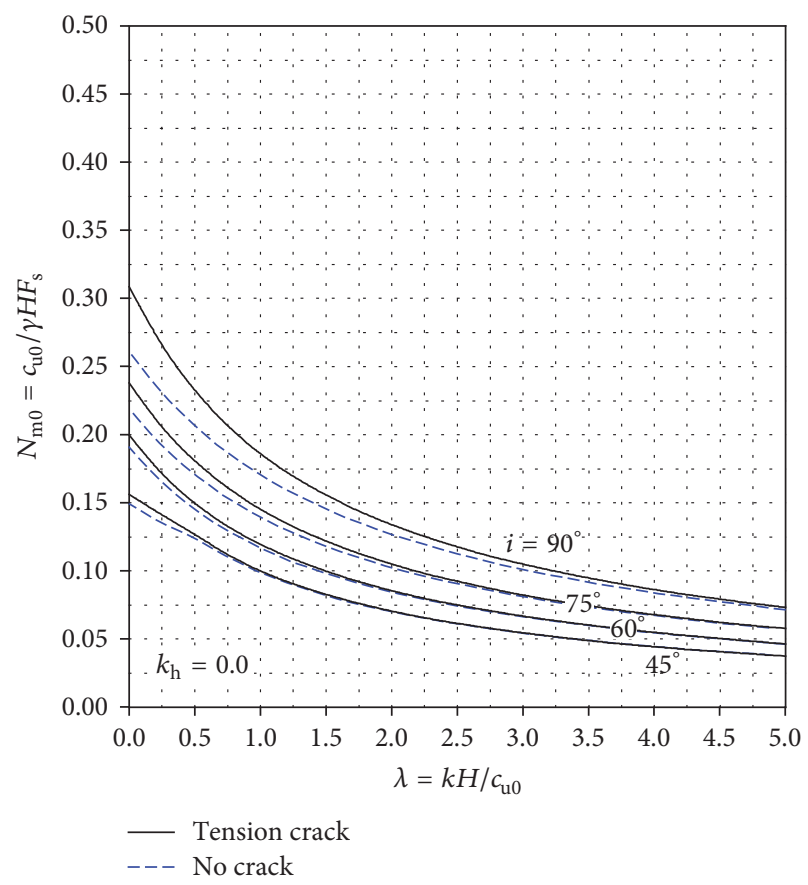

Figure 2: Stability numbers for slopes under static conditions.

slopes with tension crack are the most critical. Therefore, the comparisons indicate overestimation of the slope safety using traditional methods, because of ignoring the tension crack in clay.

3.2. Stability Charts. Using the presented procedure above, many computations are performed to produce stability charts, in which the stability number $N_{\mathrm{m} 0}$ is plotted as a function of cohesion coefficient $\lambda$. Figure 2 shows the stability chart for static cases. Noting that the solutions for slopes without cracks are also given in the chart. The chart is limited to steep slopes because of negligible impacts of the tension cracks on flat slope stability. For flat slopes under undrained conditions, their critical slip surface may tend to be much deeper and then yields unreasonable results. A constraint on the depth of slip surface should be given to assess the stability of flat slopes, as presented by Taylor [1], Hunter and Schuster [3], and Griffiths and Yu [8]. In Figure 2, the slope safety increases with increasing $\lambda$, dramatically for small value $\lambda$. The difference in the safety factor between a slope with tension crack and a slope without a crack becomes more significant as $\lambda$ decreases, especially for vertical slopes. It implies that the impact of tension crack should be considered in the excavations of cuttings in normal consolidated clay. Through the computations, the corresponding maximum depth of tension crack $\left(D_{c}\right)$ and the most adverse location of the crack $\left(L_{c}\right)$ can be obtained, as shown in Figure 3. As expected, the crack depth increases with $\lambda$ decreasing. The maximum depth of the crack can reach to $0.2 \mathrm{H}$ for vertical slopes. However, the value of $\lambda$ has minor effects on the location of the crack. The crack is almost located at $0.8 \mathrm{H}$ from the slope crest. For a sudden change for $i=45^{\circ}$ with small 
TABLE 2: Comparisons of stability number $N_{\mathrm{m} 0}$ for vertical slopes $\left(i=90^{\circ}\right)$ between lower and upper bounds of Li et al. [16] and the results of this study.

\begin{tabular}{lcccc}
\hline$\lambda$ & \multicolumn{2}{c}{ FEM-LA [16] } & \multicolumn{2}{c}{ Closed-form solution (this study) } \\
Lower bound & Upper bound & No crack & 0.3086 \\
0.0 & 0.2697 & 0.2549 & 0.2610 & 0.2641 \\
0.25 & 0.2364 & 0.2232 & 0.2301 & 0.2311 \\
0.50 & 0.2105 & 0.1984 & 0.1862 & 0.2057 \\
0.75 & 0.1900 & 0.1790 & 0.1701 & 0.1855 \\
1.00 & 0.1732 & 0.1631 & Tension crack \\
\hline
\end{tabular}

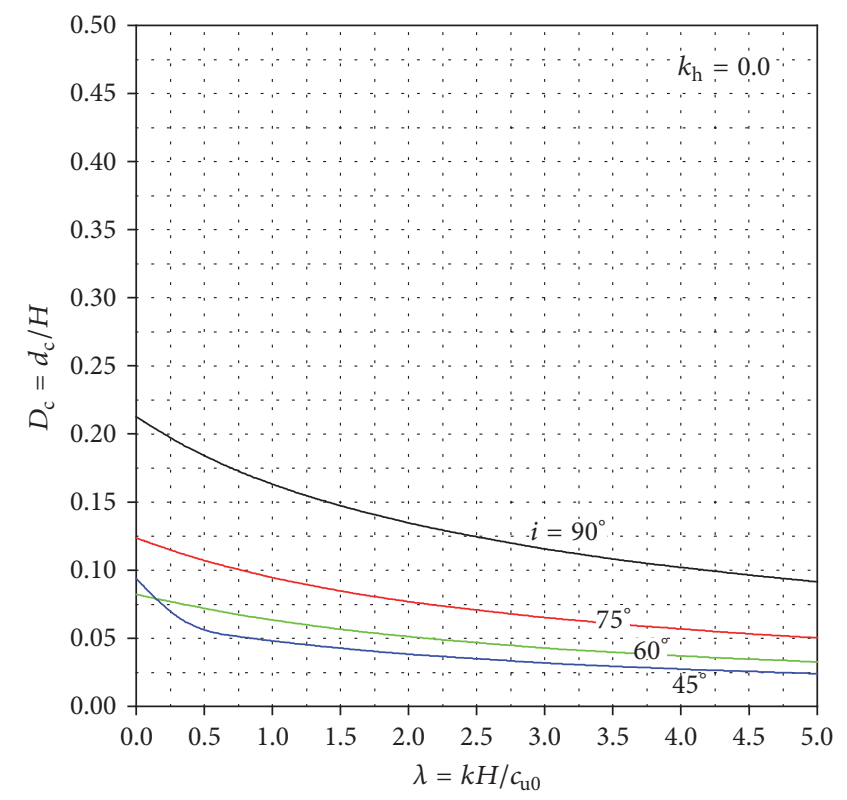

(a)

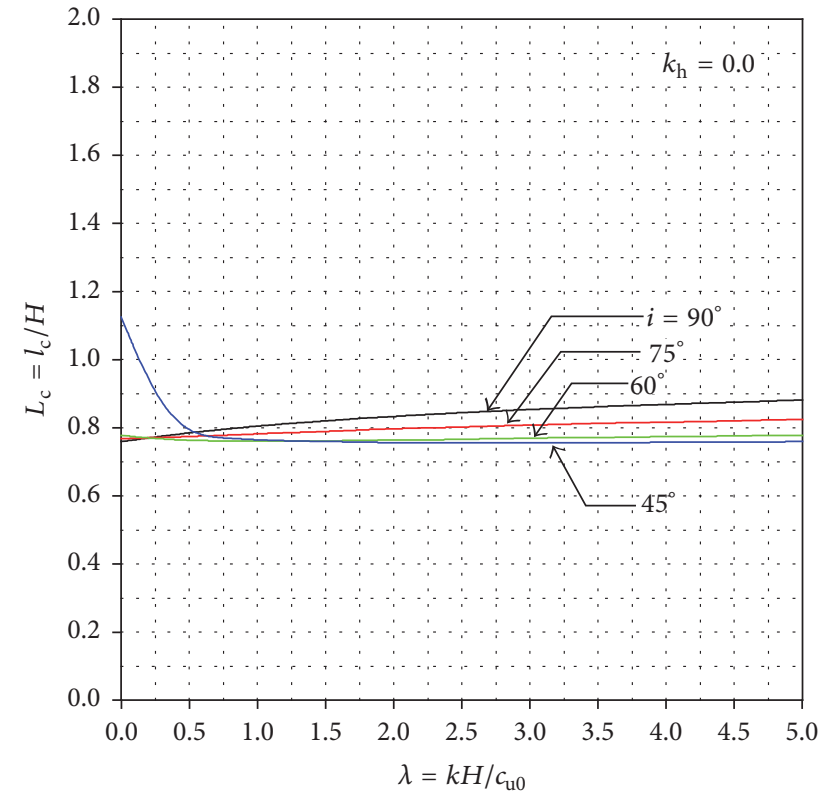

(b)

FIGURE 3: Normalized depth and location of tension crack in static slopes.

value of $\lambda$, its reason is that the deep seated failures occurred in this situation.

In the seismic cases, giving a horizontal seismic acceleration $k_{\mathrm{h}}$ can obtain the value of $N_{\mathrm{m} 0}$ and its corresponding values of $D_{c}$ and $L_{c}$. Consider that impacts of the vertical seismicity $\left(k_{\mathrm{v}}\right)$ are straightforward but ignored here $k_{\mathrm{v}}=0.0$. Figures 4-9 illustrate the charts for the stability assessment of slopes under different seismic acceleration $k_{\mathrm{h}}=0.1,0.2$ and 0.3 . The normalized values of the crack depth and location are also shown in these charts. As the seismic acceleration increases, the differences in the stability numbers between a slope with crack and one without a crack become more significant, especially for very steep slopes. Meanwhile, the maximum crack depth of seismic slopes has a dramatic increase and typically approaches to half of the slope height for vertical slopes under strong earthquakes. Figures 10 and 11 show the critical slip surfaces and the corresponding tension crack for slopes under different seismic acceleration. The critical slip surfaces obtained from analyses ignoring tension crack are also illustrated and compared with the slip surfaces with crack. Generally, the tension crack has minor influence on the critical slip surface and the distribution of the normal stress over the slip surface. However, if the crack occurred

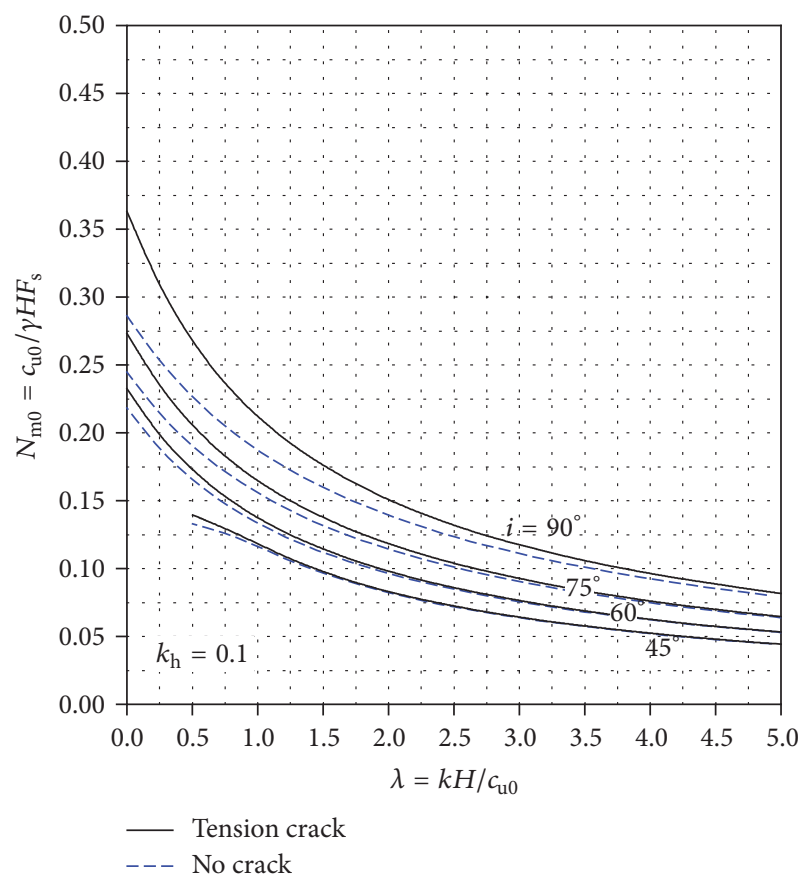

FIGURE 4: Stability numbers for slopes under seismic conditions $\left(k_{\mathrm{h}}=0.1\right)$. 


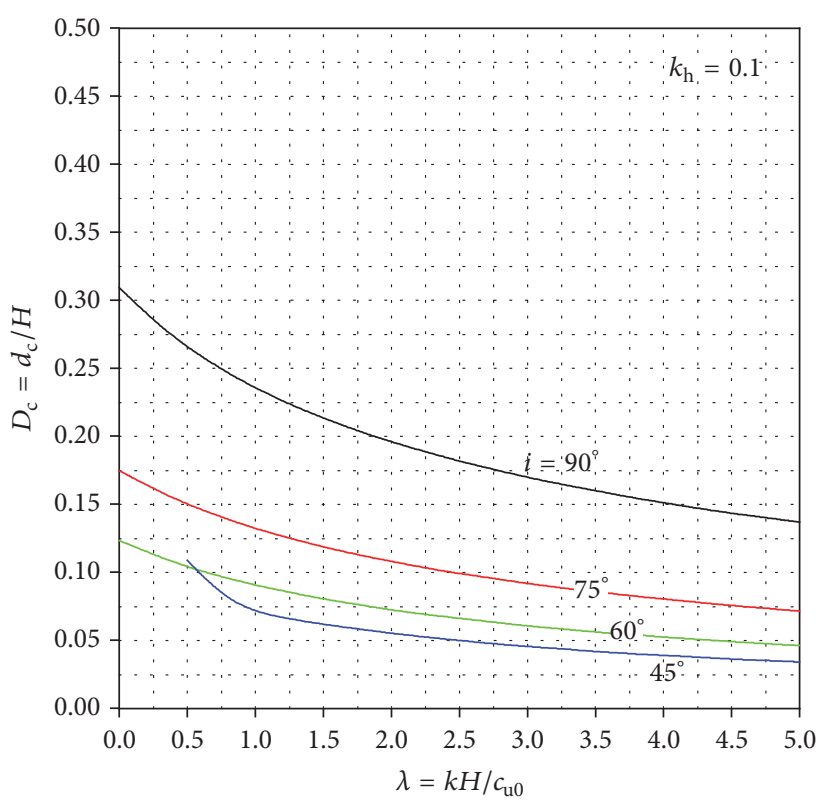

(a)

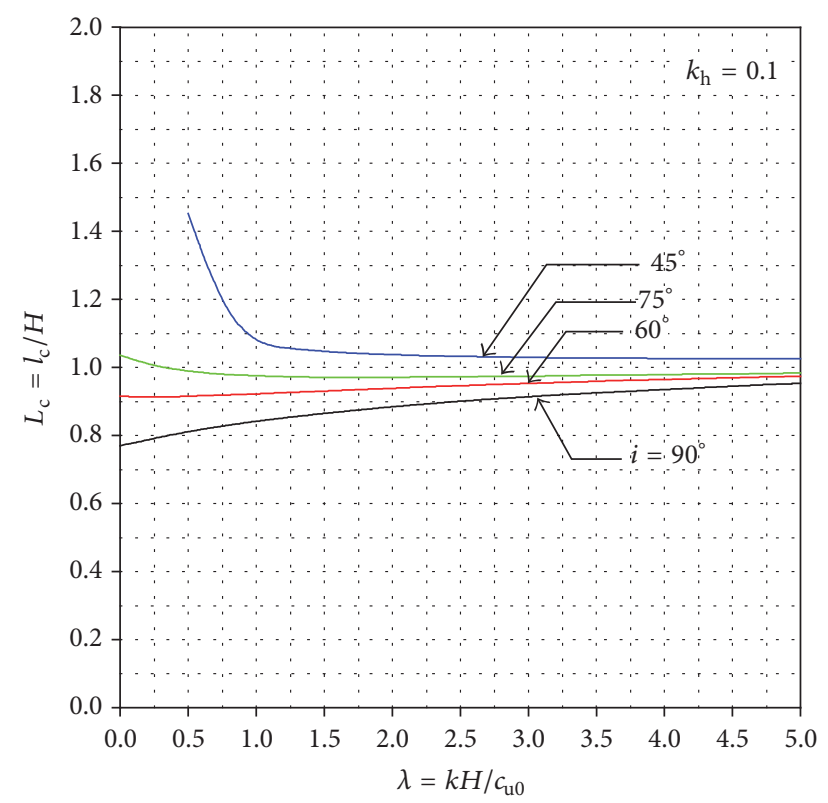

(b)

FIgURE 5: Normalized depth and location of tension crack in seismic slopes $\left(k_{\mathrm{h}}=0.1\right)$.

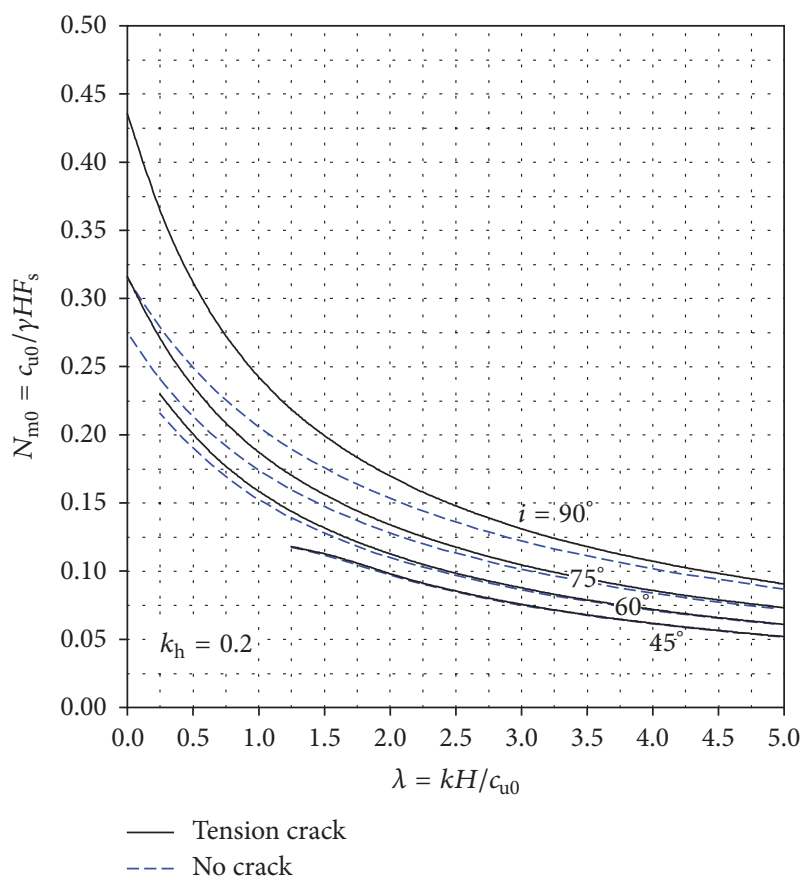

Figure 6: Stability numbers for slopes under seismic conditions $\left(k_{\mathrm{h}}=0.2\right)$.

in a seismic slope, it may seriously affect the slope safety. The potential crack can be preliminarily predicted and then prevented or controlled to make the slope stable.

3.3. Application. Using the presented charts above, one can easily obtain the factor of safety for a giving slope and predict the depth and location of the potential tension crack. A simple example is given here to show the use. A slope is built in normal consolidated clay and has slope angle $i=60^{\circ}$, height $H=10 \mathrm{~m}, \gamma=16 \mathrm{kN} / \mathrm{m}^{3}, c_{\mathrm{u} 0}=20 \mathrm{kPa}$, and $k=2.0 \mathrm{kN} / \mathrm{m}^{3}$. Firstly, calculating $\lambda=k H / c_{\mathrm{u} 0}=1.0$; Secondly, read the value of stability number from the stability chart (Figure 2) corresponding to $i=60^{\circ}$ and $\lambda=1.0$, as $N_{\mathrm{m} 0} \approx 0.12$; finally, the factor of safety can be calculated as $F_{\mathrm{s}}=c_{\mathrm{u} 0} / \gamma H N_{m 0}=$ $20 /(16 \times 10 \times 0.12) \approx 1.04$. Using another chart for the crack depth and location (Figure 3), one can find the maximum depth $D_{c}=0.06$ and the most adverse location $L_{c}=0.78$ for a potential crack.

\section{Conclusions}

Based on limit equilibrium method with variational extremization, a closed-form solution is given to evaluate the stability of slopes in clay with linearly increasing undrained strength and predict the maximum depth and the most adverse location of a tension crack. Through numerical computations, stability charts are produced in a wide range of the cohesion coefficient and then provide a tool for stability assessment of slopes in clay or design of the cuttings. Prediction of the depth and location of a potential tension crack through the charts could make its development in control and prevent water from filling with the crack. Based on the presented results, the following conclusions may be drawn:

(1) The presence of the tension crack can decrease stability of a slope in clay, significantly in vertical slopes. 


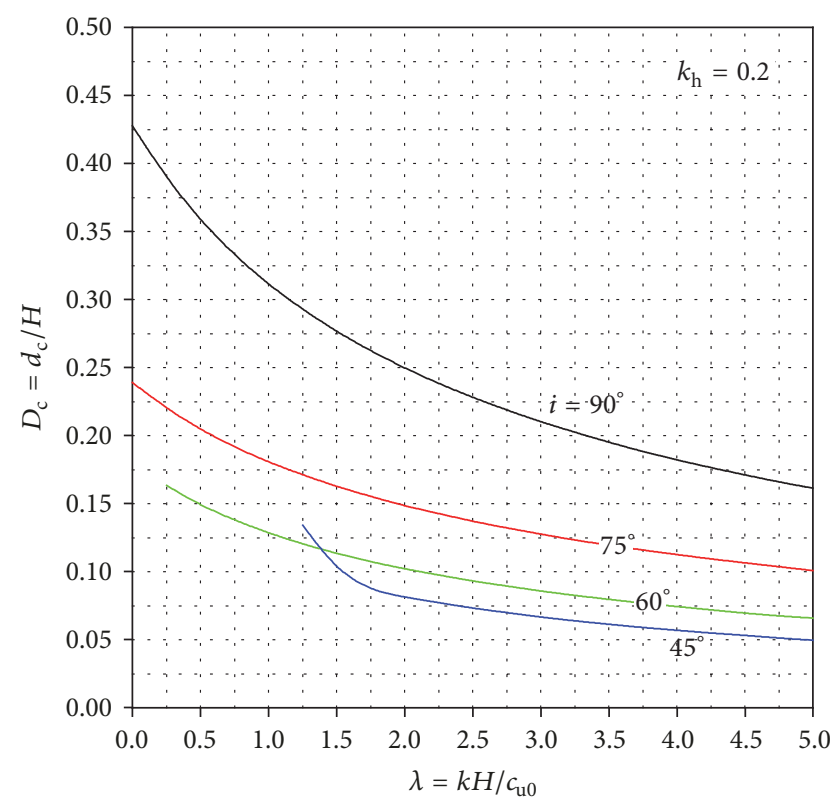

(a)

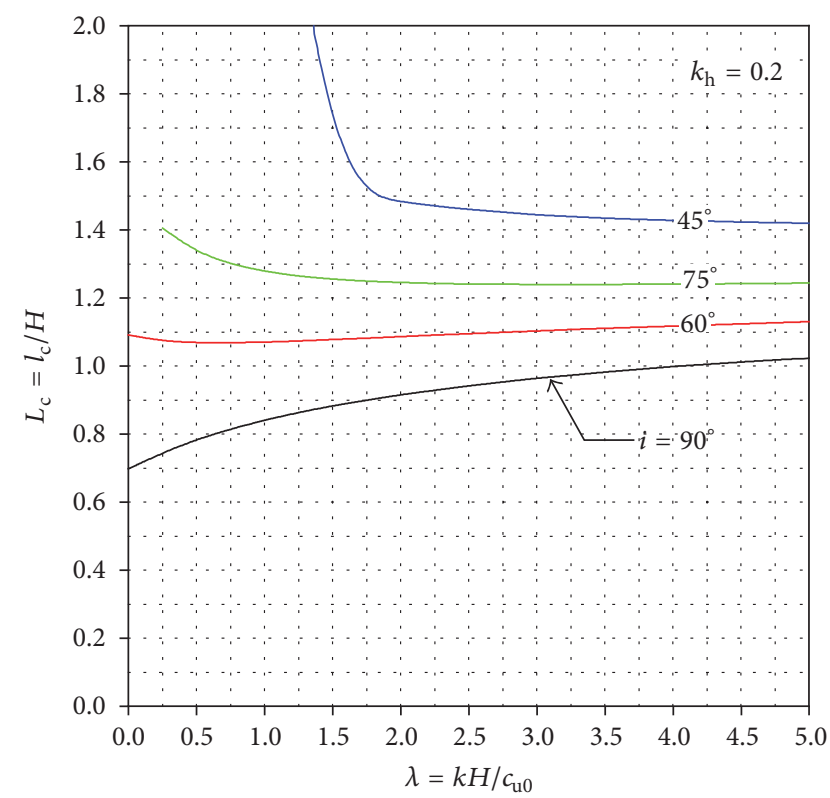

(b)

FIgURE 7: Normalized depth and location of tension crack in seismic slopes $\left(k_{\mathrm{h}}=0.2\right)$.

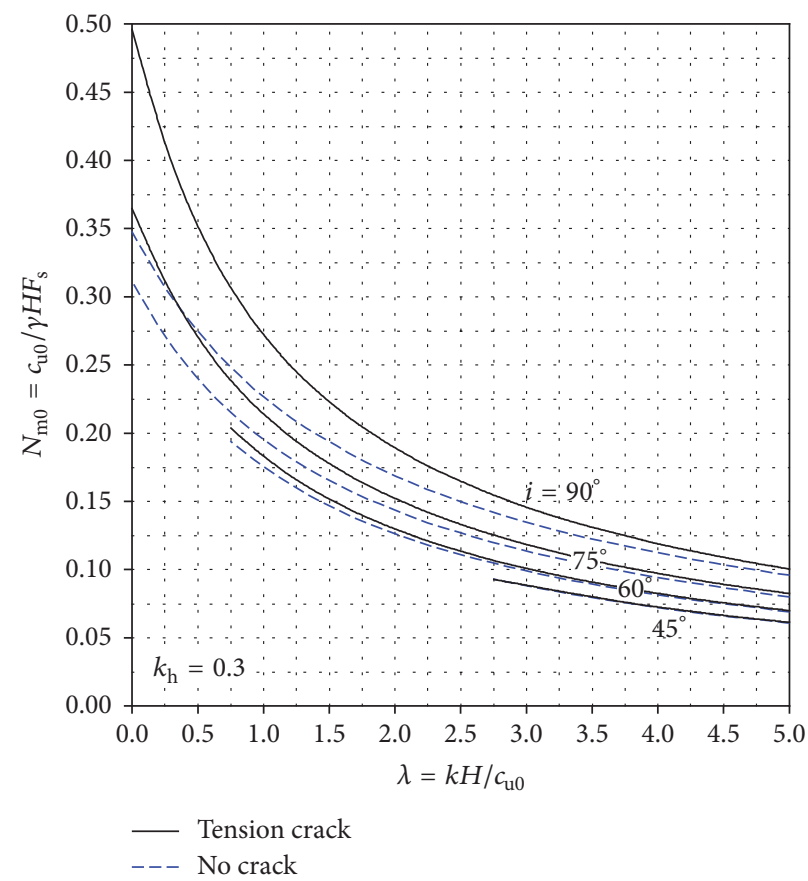

FIGURE 8: Stability numbers for slopes under seismic conditions $\left(k_{\mathrm{h}}=0.3\right)$.

Neglecting the tension crack, the overestimation on the stability can reach $20 \%$ for vertical slopes. As the strength at the crest $\left(c_{\mathrm{u} 0}\right)$ increases or the strength gradient $(k)$ decreases, the impact of the crack on the assessment of slope stability becomes more significant. The tension crack can be ignored in the stability evaluation of flat slopes (i.e., slope angle $\left.i \leq 45^{\circ}\right)$.
(2) The seismicity has dramatic influence on the safety of a slope with a tension crack. The maximum depth of the crack can approach to one-half of the slope height in vertical slopes under strong earthquakes.

(3) The cohesion coefficient $(\lambda)$ has minor impacts on the most adverse location of the potential crack. But the crack becomes farther away from the slope crest as the seismic magnitude increases. 


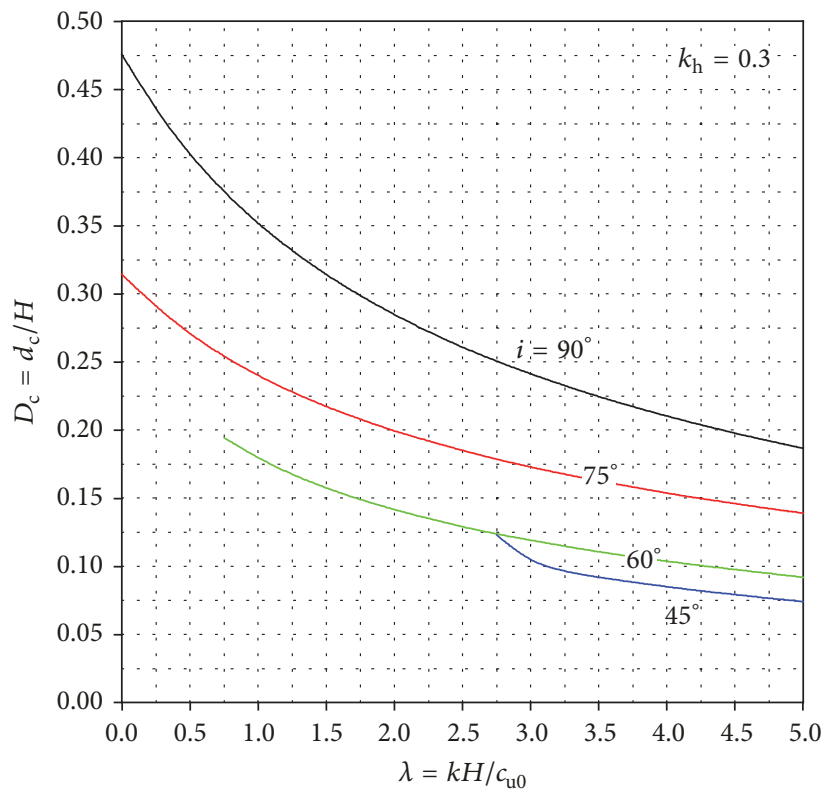

(a)

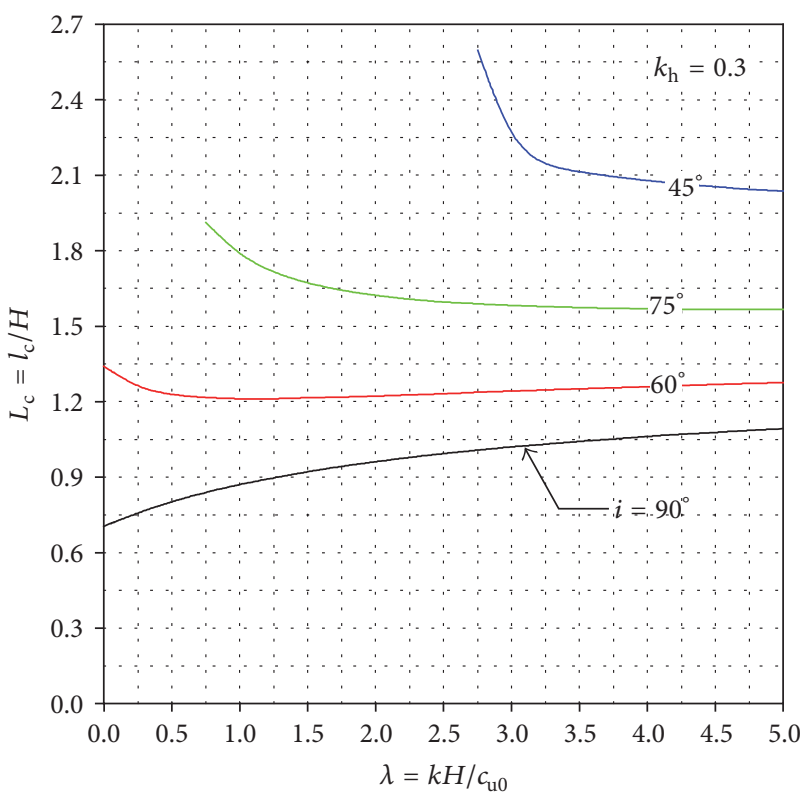

(b)

FIGURE 9: Normalized depth and location of tension crack in seismic slopes $\left(k_{\mathrm{h}}=0.3\right)$.

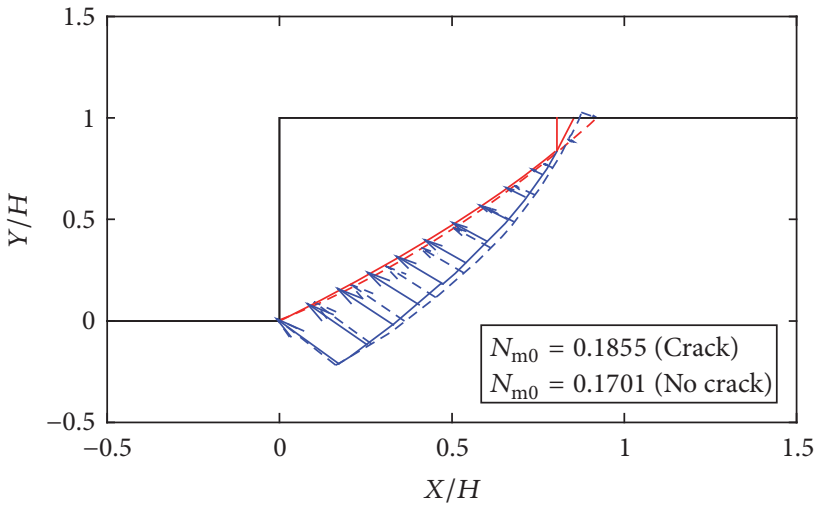

(a) $k_{\mathrm{h}}=0.0$

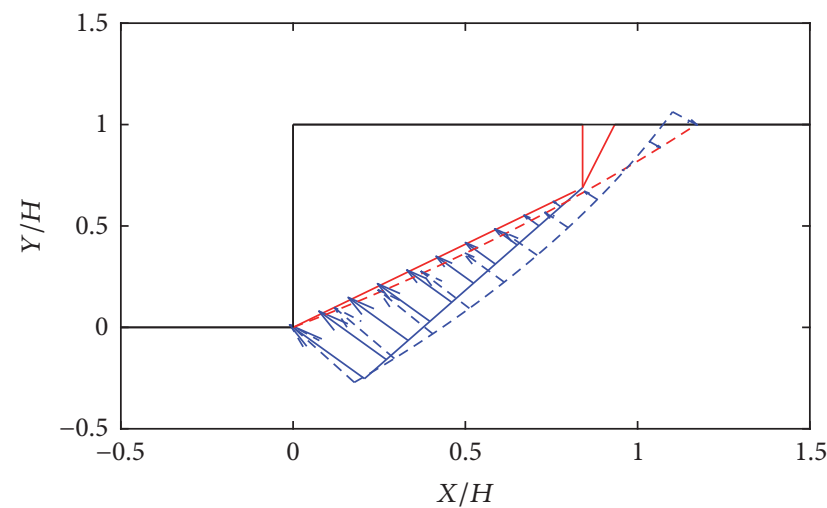

(c) $k_{\mathrm{h}}=0.2$

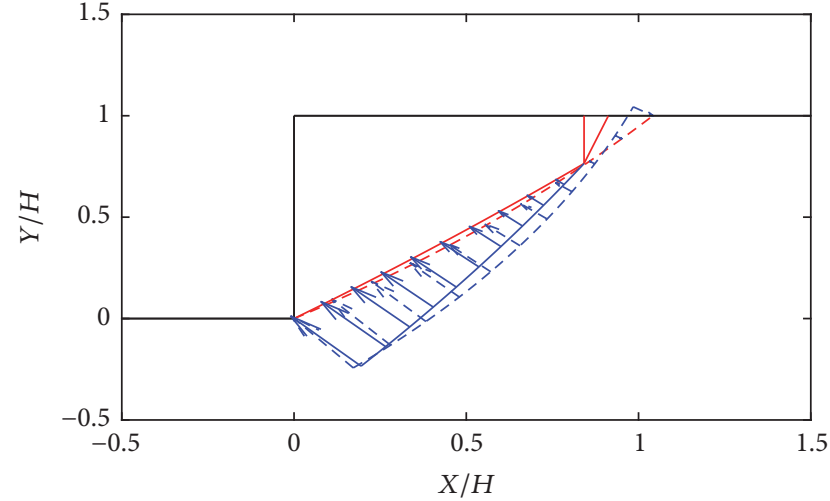

(b) $k_{\mathrm{h}}=0.1$

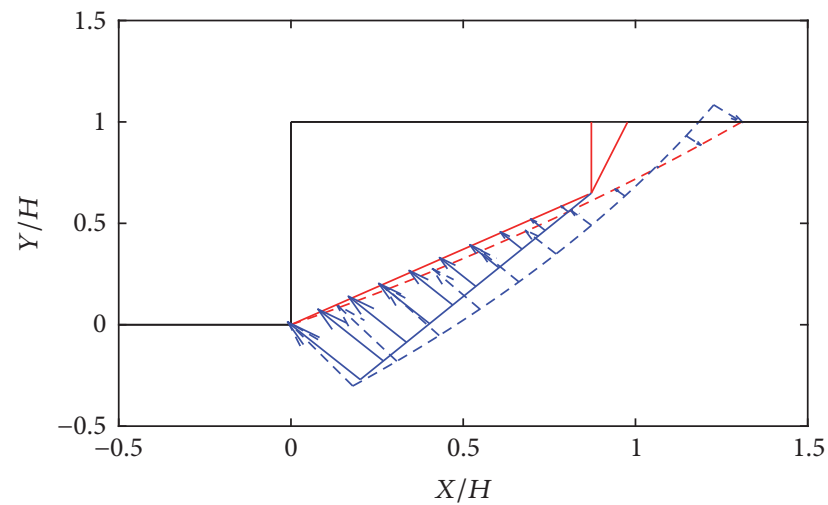

(d) $k_{\mathrm{h}}=0.3$

Figure 10: Critical slip surfaces for slope with or without tension crack $\left(i=90^{\circ}\right.$ and $\left.\lambda=1.0\right)$. 


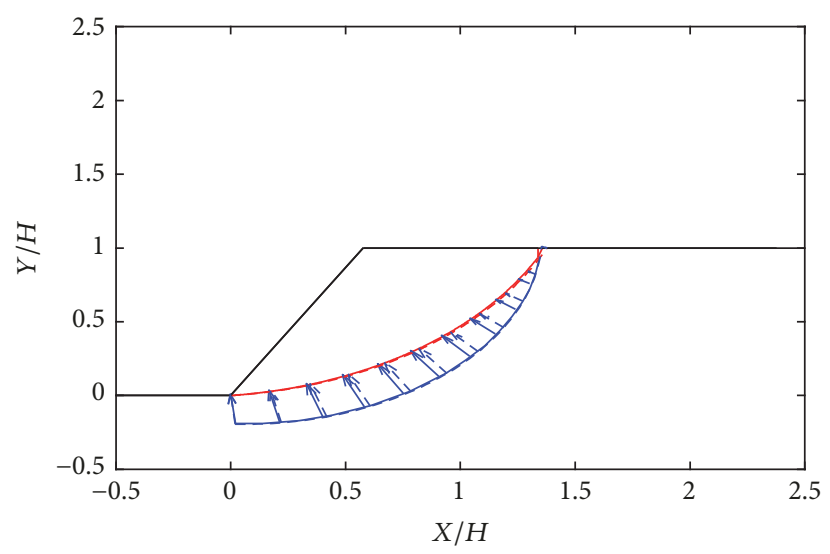

(a) $k_{\mathrm{h}}=0.0$

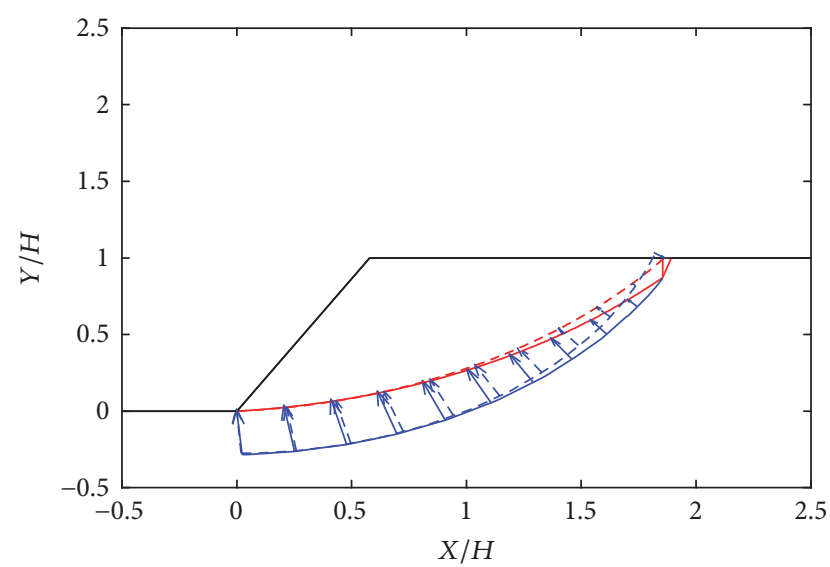

(c) $k_{\mathrm{h}}=0.2$

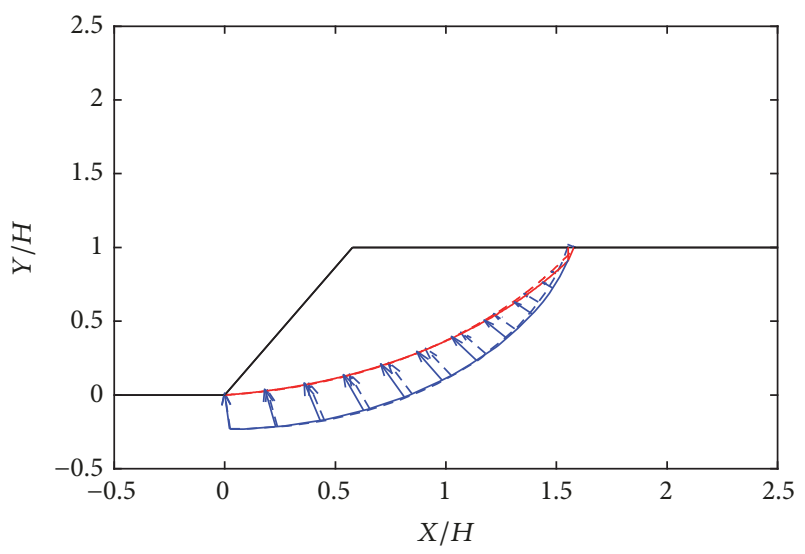

(b) $k_{\mathrm{h}}=0.1$

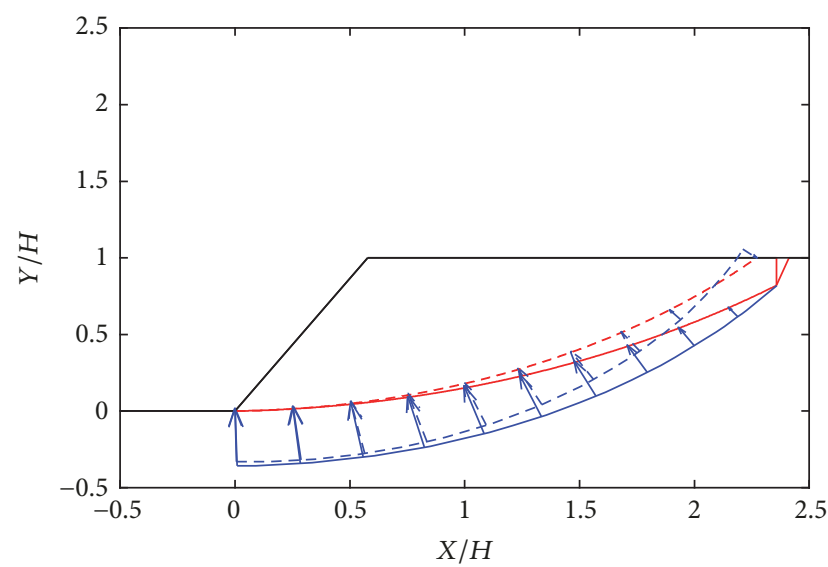

(d) $k_{\mathrm{h}}=0.3$

FIGURE 11: Critical slip surfaces for slope with or without tension crack ( $i=60^{\circ}$ and $\lambda=1.0$ ).

\section{Conflicts of Interest}

The authors declare that there are no conflicts of interest related to this paper.

\section{Acknowledgments}

This study was sponsored by National Natural Science Foundation of China (Grant no. 51578145) and the Fundamental Research Funds for the Central Universities (Grant no. 2017B00814).

\section{References}

[1] D. W. Taylor, "Stability of earth slopes," Journal of the Boston Society Civil Engineers, vol. 24, no. 3, pp. 197-246, 1937.

[2] R. E. Gibson and N. Morgenstern, "A note on the stability of cuttings in normally consolidated clays," Géotechnique, vol. 12, no. 3, pp. 212-216, 1962.

[3] J. H. Hunter and R. L. Schuster, "Stability of simple cuttings in normally consolidated clays," Géotechnique, vol. 18, no. 3, pp. 372-378, 1968.

[4] S. Odenstad, "Correspondence," Géotechnique, vol. 13, no. 2, pp. 166-170, 1963.
[5] N. Janbu, "Slope stability computations," Soil Mechanics and Foundation Engineering Report, Technical University of Norway, Trondheim, Norway, 1968.

[6] S. D. Koppula, "On stability of slopes in clays with linearly increasing strength.," Canadian Geotechnical Journal, vol. 21, no. 3, pp. 577-581, 1984.

[7] S. D. Koppula, "Pseudo-static analysis of clay slopes subjected to earthquakes," Géotechnique, vol. 34, no. 1, pp. 71-79, 1984.

[8] D. V. Griffiths and X. Yu, "Another look at the stability of slopes with linearly increasing undrained strength," Géotechnique, vol. 65 , no. 10, pp. 824-830, 2015.

[9] J. R. Booker and E. H. Davis, "A note on a plasticity solution to the stability of slopes in inhomogenous clays," Géotechnique, vol. 22, no. 3, pp. 509-513, 1972.

[10] W. F. Chen, N. Snitbhan, and H. Y. Fang, "Stability of Slopes in Anisotropic, Nonhomogeneous Soils," Canadian Geotechnical Journal, vol. 12, no. 1, pp. 146-152, 1975.

[11] H. S. Yu, R. Salgado, S. W. Sloan, and J. M. Kim, "Limit analysis versus limit equilibrium for slope stability," Journal of Geotechnical and Geoenvironmental Engineering, vol. 124, no. 1, pp. 1-11, 1998.

[12] D. Leshchinsky and D. S. Smith, "Deep-seated failure of a granular embankment over clay. Stability analysis," Soils and Foundations, vol. 29, no. 3, pp. 105-114, 1989. 
[13] B.-K. Low, "Stability Analysis Of Embankments On Soft Ground," Journal of Geotechnical Engineering, vol. 115, no. 2, pp. 211-227, 1989.

[14] J.-C. Chai, S. Sakajo, and N. Miura, "Stability analysis of embankment on soft ground (a case study)," Soils and Foundations, vol. 34, no. 2, pp. 107-114, 1994.

[15] J. Chai and J. P. Carter, "Simulation of the progressive failure of an embankment on soft soil," Computers \& Geosciences, vol. 36, no. 6, pp. 1024-1038, 2009.

[16] A. J. Li, R. S. Merifield, H. D. Lin, and A. V. Lyamin, "Trench stability under bentonite pressure in purely cohesive clay," International Journal of Geomechanics, vol. 14, no. 1, pp. 151-157, 2014.

[17] A. Nakase, "Stability of low embankment on cohesive soil stratum," Soils and Foundations, vol. 10, no. 4, pp. 39-64, 1970.

[18] R. Baker and D. Leshchinsky, "Spatial distribution of safety factors: Cohesive vertical cut," International Journal for Numerical and Analytical Methods in Geomechanics, vol. 27, no. 12, pp. 1057-1078, 2003.

[19] R. Baker and D. Leshchinsky, "Spatial distribution of safety factors," Journal of Geotechnical and Geoenvironmental Engineering, vol. 127, no. 2, pp. 135-145, 2001.

[20] R. Baker, "Tensile strength, tension cracks, and stability of slopes.," Soils \& Foundations, vol. 21, no. 2, pp. 1-17, 1981.

[21] S. Utili, "Investigation by limit analysis on the stability of slopes with cracks," Géotechnique, vol. 63, no. 2, pp. 140-154, 2013.

[22] R. L. Michalowski, "Stability assessment of slopes with cracks using limit analysis," Canadian Geotechnical Journal, vol. 50, no. 10, pp. 1011-1021, 2013.

[23] D. Leshchinsky and K.-C. San, "Pseudostatic seismic stability of slopes: Design charts," Journal of Geotechnical Engineering, vol. 120, no. 9, pp. 1514-1532, 1994.

[24] R. Baker and M. Garber, "Theoretical Analysis of the Stability of Slopes," Géotechnique, vol. 28, no. 4, pp. 395-411, 1978.

[25] D. Leshchinsky and A. J. Reinschmidt, "Stability of membrane reinforced slopes," Journal of Geotechnical Engineering, vol. 111, no. 11, pp. 1285-1300, 1985.

[26] H. I. Ling, D. Leshchinsky, and Y. Mohri, "Soil slopes under combined horizontal and vertical seismic accelerations," Earthquake Engineering \& Structural Dynamics, vol. 26, no. 12, pp. 1231-1241, 1997.

[27] R. L. Burden and J. D. Faires, Numerical Analysis, Brooks Cole, Boston, Mass, USA, 9th edition, 2010.

[28] D. Leshchinsky, R. Baker, and M. L. Silver, "Three-dimensional analysis of slope stability," International Journal for Numerical and Analytical Methods in Geomechanics, vol. 9, no. 3, pp. 199223, 1985. 


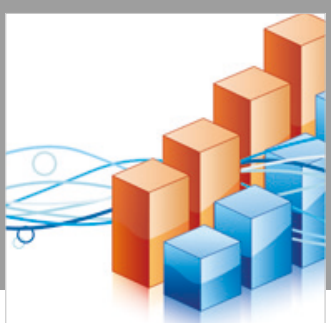

Advances in

Operations Research

\section{-n-m}
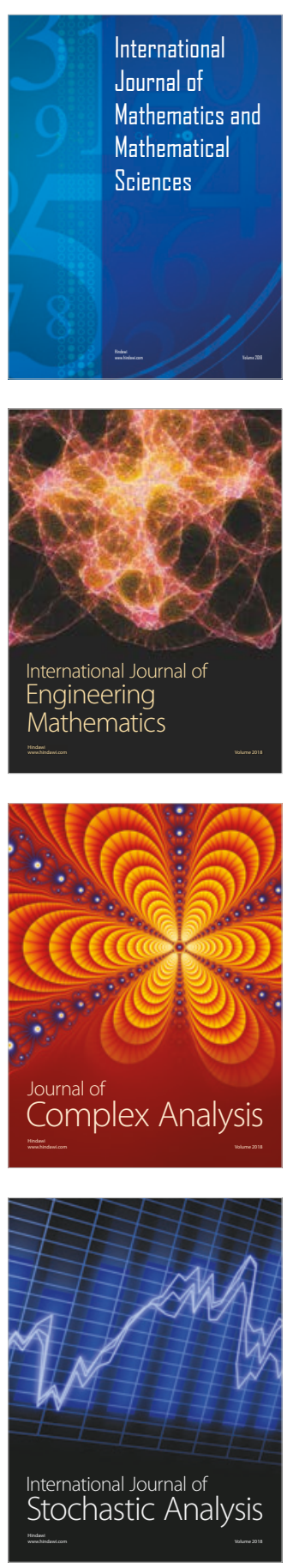
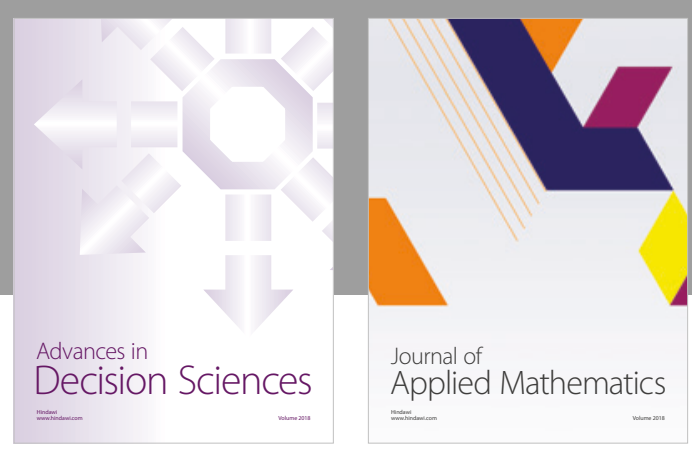

Journal of

Applied Mathematics
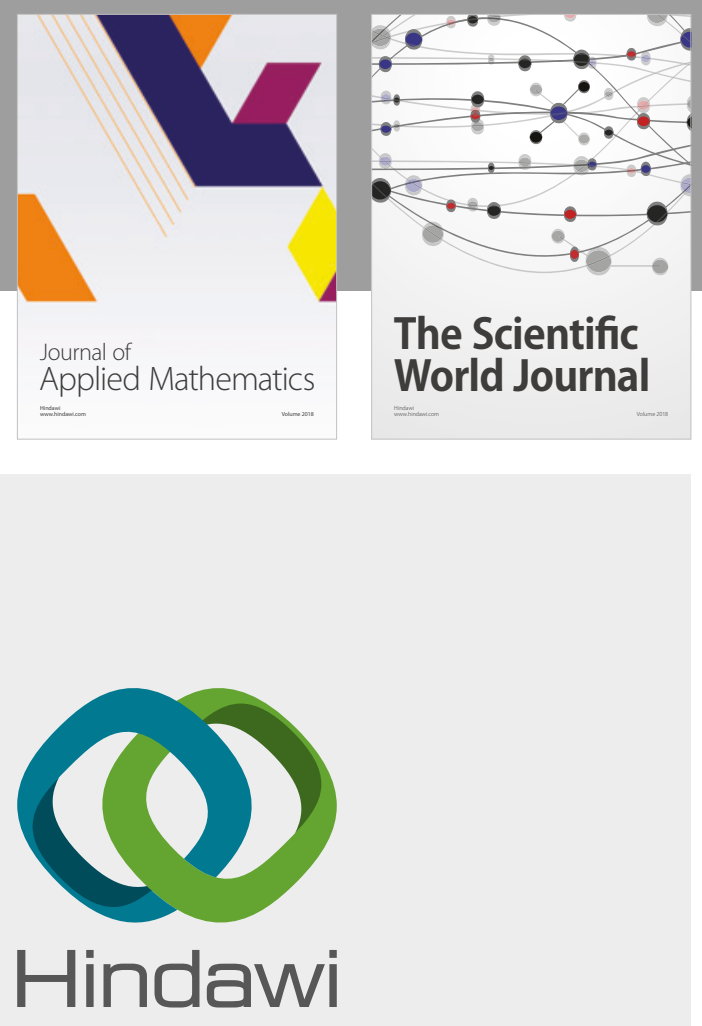

Submit your manuscripts at

www.hindawi.com

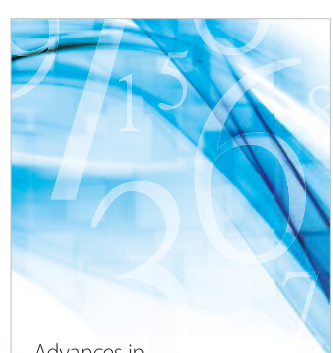

Advances in
Numerical Analysis
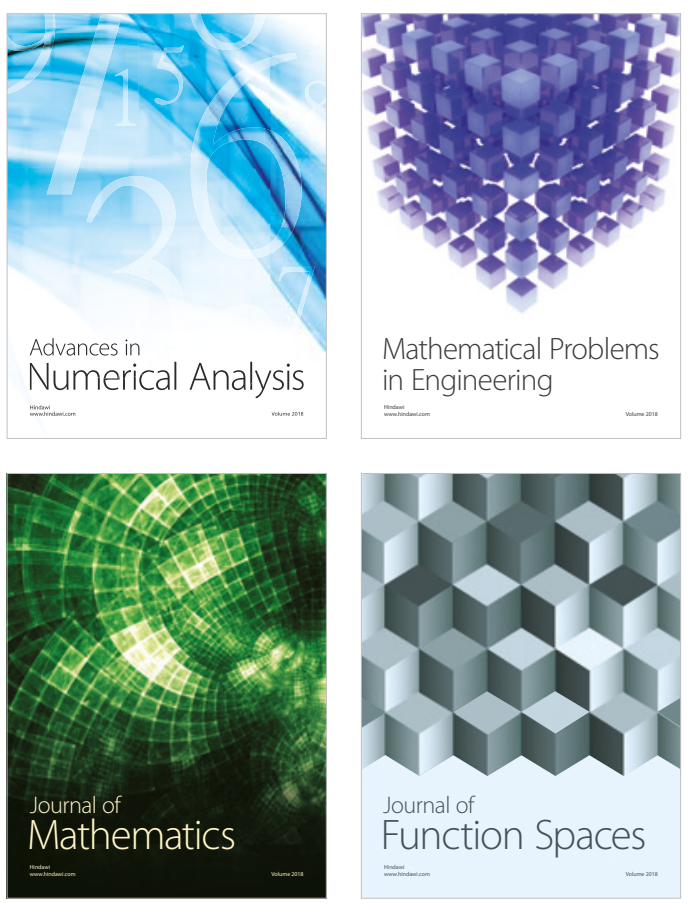

Mathematical Problems in Engineering

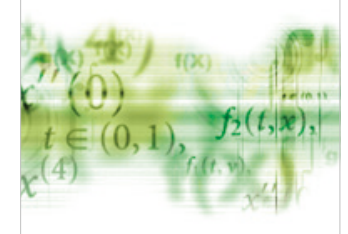

International Journal of

Differential Equations

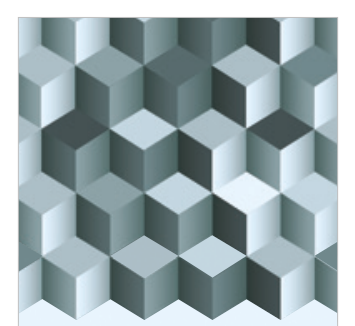

Journal of

Function Spaces

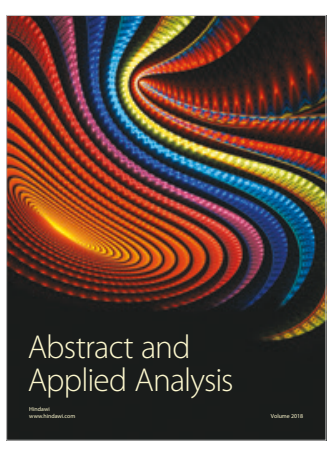

The Scientific

World Journal

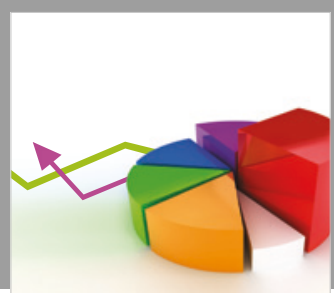

Journal of

Probability and Statistics
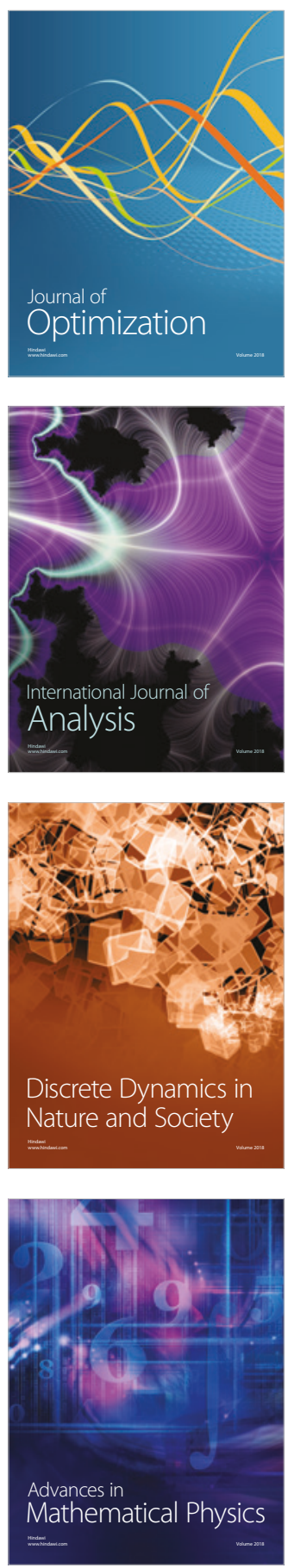